theme 1

theory

author(s) strand 1

design policies

\title{
Exercises in Geometrical Thought
}

Many of the systems and processes we encounter are changing in a continuous pattern of spiral repetition influenced by past trends. Recurring motifs that occur both in philosophical thought and in the visual arts manifest observable patterns of change. This essay analyses such a movement in design and relates to two exhibitions where this trend is brought to the fore as a central theme in contemporary design: New Olds curated by Volker Albus and Post Fossil curated by Lidewij Edelkoort. The master hand-carved wooden chair of Maarten Baas, which is a copy of the common "classical" mass-produced plastic chair, stands as an excellent example of this spiral pattern.

design theory, contemporary design, spiral, trends, tradition

\section{Introduction}

The mathematician Jacob Bernoulli (1654-1705) had the spiral form he was engaged with in his studies inscribed on his tombstone along with the phrase:

$$
\text { eadem mutate resurgo. (I shall rise up again, though changed). }{ }^{\prime}
$$

When we examine various historical processes, such as the development of economic or governing systems, no less than shifting fashions, we sense pendulum swings between poles: centralization and decentralization, democracy and totalitarianism, a focus on individuality vs. collectives in social life and even mini-skirts following maxi- and vice versa. In other fields, such as technology, science or information we observe what appears to be unidirectional movement forward. But these two modalities of progress interact. The intertwining of the pendulum and linear progress creates spiral forms: today's totalitarian regimes are not identical to past ones, and the same goes for democracy; when it comes to skirts, it is not only the length that changes. The spiral form was noted in nature as well, and was extensively studied from antiquity on, hence Jacob Bernouille's admiration for it.

Human nature displays a dual tendency: on the one hand, uncompromising pursuit of the new and the cutting edge, and on the other nostalgic yearnings and the urge to return to origins. The dialectics between the two finds its expression in design exhibitions such as New Olds (curator Volker Albus) ${ }^{2}$ and Post-Fossil (curator Lidewij Edelkoort) ${ }^{3}$ where this tendency is referred to in the titles. Both exhibitions convey the affinity for older materials and traditions that have infiltrated contemporary design. The main difference lies in the curatorial approach. 
theme 1

theory

Figure 1.

Maarten Baas (1978), Plastic Chair in Wood, 2008 strand 1

histories of design criticism

Lidewij Edelkoort, known for consistently predicting trends, approaches this phenomenon as a mood, a fresh slant that paints the world in hues of sepia, gives objects an earthy, tactile, sensuously warm quality and calls for a way of life based on natural materials and minimal use of synthetics. For Volker Albus, the turn towards the past comes from another point of view and yields a different outcome. Albus was educated in architecture and interior design, and only consequently turned to product design and curating. In his essay for the exhibition catalog, he refers to the designers' varying attitudes to the traditional or historical objects they are responding to. He looks at specific traditional sources, techniques or moments and presents an array of contemporary responses and reinterpretations of each.

Both curators address modes of responding to, quoting, and working from traditional crafts and designs. I would like to offer another perspective, with a broader, more philosophical outlook on the patterns governing relations between the past and contemporary design. I will not address or circumscribe all the works in New Olds but will focus on the creation of Maarten Baas, a piece that rather than reflecting on a single element or object points to an entire design movement (fig.1). Baas's choice corresponds well with the idea of the spiral motion underlying historical development in the art and design field.

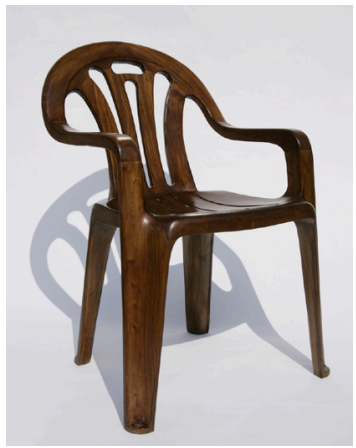

In the modern era, art and design movements characteristically presented resolute negations to the truths formulated by the movements preceding them. In our time, in contrast, the attitude is one of connection to and dialogue with the past. Since in postmodernism every artist chooses the specific place and past trend he or she wishes to relate to, the resulting map of design and artistic productions is highly dispersed. The development of the internet amplified this process through the equalizing availability of information to all. I wanted to look at this decentralization and offer an approach for reflection, a sort of "exercise in geometrical thought." My suggestion is based on formal, visual outlines of thought about the past, in this case elements that are not cast off but integrated through correlation and dialogue.

The ideational opposition of movements to those preceding them, which is characteristic of modernism, accords well with the notion of the conceptual pairs underlying metaphysical thought as delineated by one of the fathers of post-modernism, Jean Francois Lyotard. Lyotard claimed that before modernism, Western thought was based on conceptual pairs such as good and bad, center and periphery, quintessential and trivial etc., with the first indicating the qualitative and uppermost, and the second the lower and 
subordinate. His suggestion for postmodernity was to alter the relations between the terms of each pair:

"In opposition, two terms are rigidly opposed and quite distinct; in difference, the two terms are mutually implicated, yet ultimately irreconcilable. Difference is a disruptive force at the limits of discourse, indicating that no rational system of representation can ever be closed or complete, but is always opened up to forces (sensual, emotional, figural) that it cannot enclose within itself." ${ }^{4}$

One of the consequences of this shift is a culture of a-hierarchical, non-judgmental citations. These citations create structures, installations or other works that embrace diverse sources of inspiration from various periods; every part of the work is self-standing, and testifies to a source of equal value. The result is fragmentary and constructed of multiple styles and fields side by side in the same work, a combination which permits new kinds of statements to be formulated.

Another process that resonates with Lyotard's vision/suggestion to shift the scales stemmed from changing attitudes towards geographical peripheries, in whose wake came a great movement outward. American art critic Rosalind Krauss, when she identifies the presence of the grid in minimalist art, describes a centrifugal force, 5 i.e. a force spinning from the center outwards in various directions, and resulting in decentered outcomes. The contrasting force is centripetal, impelling objects inward, toward the core, exerting a strong pull from all directions into the center. My claim is that in the design world we are now witnessing a tendency towards centripetal motion, which is discussed below.

If the formative historical shift of the industrial revolution led to migrations from villages to urban centers, 150 years later the search for better ideas and quality of life drove individuals and groups out of the city, and even back to agricultural areas. As the cities expanded and solidified, and the pulse of metropolitan life accelerated, the return to nature and the yearning for secluded places grew (the need for relaxing, remote getaways contributed to this process). The pilgrimage to far-off areas resulted in a new approach towards the environment, particularly because our industrialized life-style brought on apprehension regarding global warming, as well as the overload or -- if you like -- hyperbaroque qualities that characterize our era. The theory of the spiral contends that we are at a moment that aspires to be balanced, non-fragmentary, homogenous in measure, minimalistic at the level of ideas and perhaps also materials. We now want something primary that possesses values and principles which are of benefit to our world. This requires a horizon that is not one individual's or another's, but a shared vision for a more ethical, positive life. The centripetal forces overcome unrestrained and individualized fragmentation.

The peripheral regions unveil traditions that link the past with today's world and technologies. Postmoderns will not give up technological innovations lightly, but they are well aware by now of the uncertain path on which the world is fast revolving, and are therefore attempting to find a way to integrate past and present. This is the key: consent, acceptance, invitation to and integration of past traditions, materials and wisdom with contemporary means and technologies.

The return, as I have already noted, is never to the point of origin, and does not repeat past phenomena as they were. Scottish philosopher David Hume (1711-1776) said that while repetition changes nothing in the original object, it does change the viewer's understanding. ${ }^{6}$ Two hundred years later, Gilles Deleuze discusses the significance of the 
theme 1

theory

Figure 2.

After Leochares, circa 120-140 AD, marble. $224 \mathrm{~cm}$ Vatican Museum strand 1

histories of design criticism

act of repetition in his book Difference and Repetition, stressing the significance of the act as opposed to the place or object of repetition.? Through the subject of repetition, the discussion regarding the reproduction and the original, which he addresses as well, returns yet again. Apollo of Belvedere is an excellent example (fig. 2). German art historian Johann Winckelmann (1717-1768) saw the statue as one of the most important "ideals" in the history of art (from an 18th Century perspective). The work was regarded a classic example of nobility in art. In fact, the Belvedere Apollo was a marble Roman copy of a bronze Greek original. The copy was made 500 years after the original, but nonetheless had momentous influence in pre-modern times. The question of the reproduction opens up the discussion on the value of tradition and the special standing of the work of art.

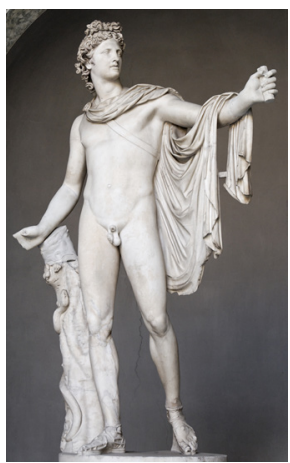

In the 19th Century, in the French Academy of Art, reproduction was inherent to the training program, and the instruction was to copy "everything beautiful." As cultural critic Stephen Bayley has noted, at the time copying was seen as an important stimulus to the development of the imagination, as they believed the copier can outdo the original. ${ }^{8}$ In Deleuze's complex reading of Nietzsche, one of the points he lingers over is the idea that for Nietzsche, the "origin means a multiplicity of differences." Deleuze therefore shows that from Nietzsche's point of view, genealogy, rather than offering an interpretation, is at its foundation an evaluation.

"Evaluation requires distancing; distancing is the element that creates the difference... his use of the past is therefore free of any admiration."9

In other words, the distance of time and place allows an appraisal of the original in light of developments over time, and along with the viewer's specific perspective, there is a possibility that the copy will improve on the source - a spiral turn par excellence.

In the design world, the discussion regarding the copy-original pair takes another turn when the object to be designed reaches the stage of mass production. At this stage, utility takes over innovation, but on the other hand, the distant is brought nearer (to the original and its aura) through reproduction. But in exhibitions such as New Olds, one generally finds one-offs with few likeness-bearing relations, such as Maarten Baas's work. And what is this work's origin?

As Walter Benjamin states, the original must be "translatable," with the translation resulting not from the object's life, but from its "survival." And while the pursuit of a 
reconnection with nature and origins can reach back to pre-historical traditions, it can also turn to objects made in the past century. In our case, the copy materializes what the original represented: a "classic" plastic chair that has become the prototype for the very definition of reproduction. Every day, millions like it are made and transported to the ends of the earth. No doubt the attitude to this item is not in the range of admiration, but rather observation, perhaps wonder as to its evolution. The translation takes place when the work reaches the age of its glory; as Benjamin tells us in The Task of the Translator, the translation does not serve the work, but owes its existence to it.10

These philosophical ideas are embedded in contemporary art making. The concepts of intertwining the binary couples of Western thought, rewriting schemes of operation or production and incorporating translation as an integral part of the work or as a core factor are central to Maarten Baas's work. In her exhibition, Lidewij Edelkoort sees him as "an early and influential player of the Post-Fossil movement" and in the context of Volker Albus's New Olds, he corresponds both to a recent and to a more distant past.

The piece I chose to focus on to highlight my point is Plastic Chair in Wood from 2008, which was part of the New Olds exhibition. The form of Baas's chair is identical to the original, but the idea is converse -- not the popular plastic chair, but a hardwood one-off. The potential for an assembly line that produces millions of chairs rests almost exclusively in China. Baas, on the other hand, restores to the Chinese the virtuoso craftsmanship that was the glory of traditional China, and asks a Chinese master to hand carve a chair which was originally mass produced in plastic. An encounter, perhaps even a head-on collision between the knowledge amassed by assembly-line expertise of the world's most prevalent, mega-popular plastic chair, which has become iconic, and the spiral return to carved wood that bespeaks warmth both as material and as a reminder of a uniquely hand-crafted object. The technique of mechanical reproduction, claims Benjamin, separates the reproduced object from the domain of tradition." The multiplicity of copies replaces the singular existence of the original. Even a perfect copy is missing one thing: the presence of time and space, the singular experience of the place it belongs to, the situation of the original. This is the initial demand of authenticity. In Maarten Baas's chair we can find traces of the "authenticity" that supports widespread distribution: the dents along the chair legs that serve for maximal piling of chairs onto containers. This fits a plastic chair, but is not similarly apprehended in the hardwood design.

Thus in design, as in numerous other domains, the flow of centripetal influences may open a space wherein items that dominate the periphery, and even represent it to some extent, turn into a one-of-a-kind, sensuous object which exposes the formal curves that looked so odd in plastic, and appear so natural when carved in wood. A kind of vertiginous pull exerts itself from the ends of the world to a unique item that opens a new horizon of possibilities before us.

\section{References}

'http://www-history.mcs.st-andrews.ac.uk/history/Biographies/Bernoulli_Jacob.html

${ }^{2}$ New Olds - Design between Tradition and Innovation, curator: Volker Albus, published by Institute for Foreign Cultural Relations, Stuttgart. Design Museum, Holon, 2011

${ }^{3}$ Post Fossil - excavating 21st century creation, curator: Lidewij Edelkoort. This exhibition was first commissioned by 21_21 Design Sight and expanded for Design Museum, Holon, 2011 
${ }^{4}$ Internet Encyclopedia of Philosophy, Jean Francois Lyotard, Reason and Representation http://www.iep.utm.edu/lyotard/

${ }^{5}$ Krauss, R. (1979) "Grids," in October, Vol. 9, pp. 50-64 (Summer, 1979), Cambridge: MIT Press, pp. 50-64.

${ }^{6}$ Hume, D. (1739) A Treatise of Human Nature, sect. XIV: Of the Idea of Necessary Connexion,.Project Gutenberg, 2010 http://www.gutenberg.org/files/4705/4705h/4705-h.htm

7 Deleuze, G. (1986) Difference and Repetition, trans. Paul Patton, New York: Columbia University Press, p. 295

${ }^{8}$ Bayley, S. (2000) General Knowledge, London: Booth-Clibborn Editions, p.77.

${ }^{9}$ Deleuze, G. (1983) Nietzsche and Philosophy, New York: Columbia University Press, p.8

${ }^{10}$ Benjamin W. (1923) "The task of the Translator," in The Translations Studies Reader, ed. Lawrence Venuti (London: Routledge, 2000)

"Benjamin W. (1936) "The Work of Art in the Age of Mechanical Reproduction," trans. Harry Zohn in Benjamin Illuminations, London: Jonathan Cape 1970, p. 301

\section{Acknowledgements}

Nirith Nelson's participation at the conference was supported by the Embassy of Israel in Portugal. 